\title{
Preparation and Characterization of Metal Membranes for Gas Separation
}

\author{
Kyriaki Drakaki ${ }^{1}$, George Bomis ${ }^{1}$, Sofia Kavafaki ${ }^{1}$, Athanasios Varoutoglou ${ }^{1}$, George Z. Kyzas ${ }^{1(D)}$, \\ Athanasios C. Mitropoulos 1,* \\ 1. Department of Chemistry, International Hellenic University, Kavala 65404, Greece;drakakhkyriakh@ hotmail.com (K.D.); \\ bomis@teiemt.gr (G.B.); sofiakvf@gmail.com (S.K.); atavaro@chem.ihu.gr (A.V.); kyzas@chem.ihu.gr (G.Z.K.); \\ * Correspondence: amitrop@chem.ihu.gr (A.C.M.);
}

Scopus Author ID:6603728778

Received: 13.08.2021; Revised: 20.09.2021; Accepted: 25.09.2021; Published: 16.10.2021

\begin{abstract}
The purpose of this article is the characterization of permeability and the ideal selectivity of new metallic brass membranes with a "sandwich" structure. Characterization is an important factor related to the morphology, structure, and properties of the membrane. The membranes were examined for simple gas phases, including various exogenous factors on their performance (temperature, pressure, durability). To evaluate their performance, permeate measurements were made at temperatures from 18 to $300^{\circ} \mathrm{C}$ and at various pressures from 1 to 10 bar. Results have shown that permeability is influenced by the molecular weight and exhibits ideal selectivity greater or equal by Knudsen's ideal separation factor in a sequence of $\mathrm{H}_{2}>\mathrm{He}>\mathrm{CH}_{4}>\mathrm{N}_{2}>\mathrm{O}_{2}>\mathrm{Ar} \geq \mathrm{CO}_{2}$. The permeability is also a function of the thickness of the membrane, as it shows there's a decrease in permeability and an increase in selectivity when the thickness is increased. The effect of temperature on these metal membranes is considered an important factor in the operation of membranes and membrane systems. The main feature is the reduction of permeability with the increase of temperature.
\end{abstract}

Keywords: metallic membranes; brass; permeability; Knudsen's selectivity;gas separation.

(C) 2021 by the authors. This article is an open-access article distributed under the terms and conditions of the Creative Commons Attribution (CC BY) license (https://creativecommons.org/licenses/by/4.0/).

\section{Introduction}

Membrane gas separation technology have attracted high interest and attention of researcher for the last few years and today are used extensively for a wide range of industrial applications [1] as it has proven to be a highly energy-efficient, cost-effective, and environmentally friendly nature benign approach to gas separation [2-5] compared to other separation methods [6-7].

The membrane is the "heart" of the separation process [8] and is defined as a thin natural barrier that allows the selective transfer of components or molecules between two phases. Membranes function as filters that allow specific molecules to permeate while blocking certain molecules based on size and other physical/chemical properties [1]. Each component has a different ability to pass through a membrane (polarity, interaction, and affinity) [9]. For this reason, a driving force is needed to move from one phase with retention of the other components [10] to another resulting in different recommendations on the side to which the molecules are transported [11-13].

Characterization is an important factor related to the morphology, structure, and properties of the membrane. A small change in the configuration parameters can change the upper layer of the structure and give different results in the operation of the membrane. 
Depending on their geometry, the membranes may have a flat or tubular, spiral, or thin porous sheet arrangement.

Flat membranes are the simplest construction descriptively and are mainly used on a laboratory scale [14]. To date, there are more than 400 types of membranes commercially available worldwide. Among them, most are organic and metal films with $\mathrm{Ni}, \mathrm{Pd}, \mathrm{Ag}$, and stainless steel limitation. The companies for producing inorganic films are 144, with 94 of them specializing in ceramic films and 36 in metal films [15].

\subsection{Metallic membranes.}

Membranes that can be made available for industrial use other than polymeric are metal films. The base materials for metal membranes are metals, while selective materials are metals, metal oxides, or metal alloys [15-16]. Most of them are characterized by a graded composite structure which mainly consists of a primary base that provides mechanical strength and a separation layer that allows permeating the gas into the surface pores of substrates [9].

One of the many advantages of metal membranes, mostly palladium (Pd)-based membranes, is the selectivity to $\mathrm{H}_{2}(\sim 100 \%)$ and high flux without sample defects at high temperatures of $300-600^{\circ} \mathrm{C}[17-19]$.

They also have significant mechanical strength and high flow. The disadvantages that have limited their application on a large scale are the low permeability and especially the high cost of metal $[16,20]$. Consequently, the cost of the system is proportional to the square of the thickness of the metal layer, and precious metal films must be extremely thin to be costeffective.

Also, some metallic membranes that have been used for $\mathrm{H}_{2}$ purification show sensitivity in the presence of chemicals gases such as $\mathrm{H}_{2} \mathrm{~S}, \mathrm{HCl}$, and $\mathrm{CO}$, which can be adsorbed on the surface of the membrane, resulting in its "poisoning" and blockade the dissociation sites. The exclusion of sites can be sufficient to reduce hydrogen flow at a rate of 20 to $100 \%[14,21$ 25]. These problems can be reduced by reducing the thickness of the selective layer but maintaining its mechanical strength. However, they are considered attractive due to their high chemical, thermal and mechanical resistances, excellent separation characteristics, and long service life [8].

In this experimental study, an attempt was made to make thin films from metal materials such as brass, where the required minimum possible cost of materials is an original effort.

\subsection{Gas separation.}

Membrane gas separation methods are modern physical separation in chemical engineering processes and could reduce capital investment, operating costs, and the safety of this process [26-27]. Separation is the most important operation in gas-related industries [6,28]. New constant developments in metal membranes have shown significant improvements that have successfully led to $\mathrm{H}_{2}$ separation, $\mathrm{CO}_{2}$ capture, organic vapor removal, LPG recovering, etc. [2,13,29-30]. The mechanism of gas transfer through metal membranes is the key to their highly selective permeability.

An issue in the development of metal films is to make the metal layer thin enough to achieve high flows, but it must also be strong enough to withstand operating pressures [24]. Membranes with an ultrathin thickness that can achieve high permselectivity and mechanical stability are desired by energy and gas-related industries [2]. 
The gas transfer mechanism through most metals can be divided into two types: (i) solution diffusion for dense and metallic membranes such as Pd membranes and (ii) Knudsen diffusion or combined Knudsen diffusion mechanism, and surface diffusion for porous metal membranes [21,31].

Permeability and selectivity are two important concepts directly related to gas separation [9-10,31]. A measurement of the permeability properties of a gas is the simplest and most reliable method of characterizing membranes. Permeability measurement is the basic method of characterizing materials, as information is collected about their structure and the size of the material pores.

Permeability is described by the general relationship [10,13,31]:

$$
\mathrm{Pe}=\frac{\mathrm{NA} * \mathrm{~L}}{\Delta \mathrm{P} * \mathrm{Am}}[=] \frac{\mathrm{mole} * \mathrm{~m}}{\mathrm{~m}^{2} * \mathrm{~Pa} * \mathrm{~s}}
$$

$\mathrm{Pe}=$ the permeability, $\mathrm{NA}=$ gas flow $(\mathrm{mol} / \mathrm{sec}), \Delta \mathrm{P}=$ the pressure difference on the sides of the membrane $(\mathrm{Pa})$, $\mathrm{Am}=$ the flow surface of the membrane $\left(\mathrm{m}^{2}\right), \mathrm{L}=$ film thickness $(\mathrm{m})$

In this study, and due to their structure, the actual thickness of the membranes can only be calculated through the SEM (scanning electron microscope) because of the layers of which the metal membranes are composed. For this reason, permeation values are calculated in GPUs.

$$
\mathrm{Pe}=\frac{\operatorname{Vlow}\left(\mathrm{cm}^{3}\right) * \frac{\Delta \mathrm{P}}{\Delta \mathrm{t}}\left(\frac{\mathrm{mbar}}{\mathrm{min}}\right)}{\mathrm{S}\left(\mathrm{cm}^{2}\right) * \mathrm{Ph}(\mathrm{mbar}) * \operatorname{Trig}(\mathrm{K}) * 60\left(\frac{\mathrm{sec}}{\mathrm{min}}\right) * 83167.3\left(\frac{\mathrm{cm} \mathrm{mbar}^{3}}{\mathrm{~mol} * \mathrm{~K}}\right) * 10^{-4}\left(\frac{\mathrm{m}^{2}}{\mathrm{~cm}^{2}}\right) * 100\left(\frac{\mathrm{Pa}}{\mathrm{mbar}}\right)}
$$

The GPU (Gas Permeability Unit), expressing the volumetric flow of gas through the membrane under normal conditions $\left(1 \mathrm{~atm}, 0^{\circ} \mathrm{C}\right)$, per unit thickness of a membrane and unit of the partial pressure of diffuser through the membrane [9-10, 31]:

$$
1 \mathrm{GPU}=3.35 \times 10^{-10 \mathrm{~mol}} /\left(\mathrm{m}^{2} * \mathrm{~s} * \mathrm{~Pa}\right)
$$

Selectivity indicates the extent of separation of the gas of a component from a mixture of gases [13]. The ideal selectivity of a membrane is calculated from the permeation of two pure gases and is defined as [10]:

$$
\mathrm{S}_{1 / 2}=\mathrm{Pe}_{1} / \mathrm{Pe}_{2}
$$

\subsection{Knudsen diffusion.}

The transport of gases through porous membranes is done through the Knudsen type diffusion that is observed mainly in the intermediate membranes, when their pores have a diameter much smaller than the average free path of the gas $(\mathrm{dp} / \lambda<1)[9-10]$ :

$$
\mathrm{K}_{\mathrm{n}}=\frac{\lambda}{\mathrm{d}_{\mathrm{p}}}
$$

$\lambda=$ the average free path of the gas, $\mathrm{dp}=$ the characteristic diameter of the pores

In any collision with the pore wall, the molecules are momentarily adsorbed and then reflected randomly [13]. This separation of gases is achieved due to the different velocities of the different gases. Therefore what determines the rate of gas diffusion through the membrane 
is the molecular weight of the gas is with the lighter gases being diffused faster within the membrane. Based on the Knudsen diffusion, the selectivity (i.e., the ideal separation factor) of an A-B gas pair is given by the mathematical expression [31-32]:

\section{$\sqrt{\mathrm{MB}} / \mathrm{MA}$}

When the Knudsen number is much smaller than the unit $(\mathrm{Kn}<<1)$, the laminar flow mechanism occurs in porous media carrying large pores. Accordingly, the Knudsen diffusion mechanism prevails if the dimensionless number is higher than the unit $(\mathrm{Kn}>>1)$. The Knudsen diffusion mechanism occurs mainly in relatively small pores. The above mechanism presents high permeability values both at high temperatures and in corrosive environments successfully.

\section{Materials and Methods}

\subsection{Membrane materials.}

The metal membranes were manufactured at the laboratory of the Department of Mechanical Engineering at the International Hellenic University in Kavala. Twelve brass metal films (DIN 17660) were fabricated and selected with a composition of $57.95 \% \mathrm{Cu}, 37.92 \% \mathrm{Zn}$, $3.65 \% \mathrm{~Pb}$, all in the form of a disk with an outer diameter $\Phi 35$, but with an active alternating surface $\Phi 2$. Membrane thickness was from $0.080 \mathrm{~mm}$ to $0.205 \mathrm{~mm}$ and characterized for singlephase permeability experiments, with the gases $\mathrm{H}_{2}, \mathrm{~N}_{2}, \mathrm{CO}_{2}, \mathrm{O}_{2}, \mathrm{Ar}, \mathrm{CH}_{4}$, $\mathrm{H}_{e}$. Their structure is a sandwich-type, consisting of the membrane (internal) and two identical outer layers of metal oxide. All membranes followed a cleaning protocol, through stages of removal process residues that their presence may affect the permeability. To remove the surface adhesions of the metal membranes washed with a) deionized water and b) isopropanol in two phases, at 35 $\mathrm{W}$ and $50 \mathrm{~W}$ for $240 \mathrm{sec}$ and $180 \mathrm{sec}$, respectively, in an Ultrasonic cleaner device. After the cleaning protocol, the membranes were placed onto a burner at a temperature range of 150$180^{\circ} \mathrm{C}$ to absorb all the water vapor and gases that have been adsorbed and would have a decisive effect on permeability.

\subsection{Permeability.}

The method is based on a dead-end mode (and "open"- crossflow) structure that leads to a bubble meter as it is used to measure the specific flow of gases (pure components) $\left(\mathrm{H}_{2}\right.$, $\mathrm{He}, \mathrm{CH}_{4}, \mathrm{~N}_{2}, \mathrm{O}_{2}, \mathrm{Ar}, \mathrm{CO}_{2}$ ) at different supply pressures (1-10 bar) [13]. The gas molecules from the high-pressure space diffuse into the metal membrane, permeate it, and then are led to the low-pressure space as it is under pressure (vacuum), in pressure over time ( $\Delta \mathrm{p} / \Delta \mathrm{t})$ [6]. In the permeability experiments, all flat membranes were initially placed on a metal substrate and sealed in the stainless-steel metal cell using O-rings-Viton for high pressures. Before the operation of the device, leaks were checked at a pressure of 60 bar. The membranes are thin as their thickness ranges from 0,060 to $1,200 \mathrm{~mm}$, and for this reason, it is necessary to support them to avoid various deformations that would affect their permeability through a perforated metal substrate to ensure the required stability of the membrane [13]. The parameters pressure, temperature, and time are recorded electronically with a USB connection with a special software program to calculate the GPU (Gas Permeation Unit) values of the gases in units of $\mathrm{mol} / \mathrm{m}^{2} * \mathrm{~Pa}^{*} \mathrm{~s}$. 


\subsection{Temperature.}

To evaluate the membrane performance, single-phase permeance measurements of pure components (individual gases) were performed at a temperature range from $-18^{\circ} \mathrm{C}$ to $300^{\circ} \mathrm{C}$ and various pressures (1-10 bar) using the variable volume method. Maintaining a constant pressure difference on both sides of the membrane, the flow rate of the gases on the filtrate side is measured with the help of a bubble gauge. The first experiments were performed using $\mathrm{N}_{2}$ and $\mathrm{H}_{\mathrm{e}}$ on a brass membrane to study their permeability and the behavior of permeability as a function of pressure. Then measurements were made in the temperature range 23 to $300^{\circ} \mathrm{C}$ for gases with constant pressure at 10 bar.

\section{Results and Discussion}

\subsection{Permeability-selectivity.}

From the experiments' measurements, the membranes with a thickness of $0.085 \mathrm{~mm}$, $0.196 \mathrm{~mm}$, and $0.205 \mathrm{~mm}$ were selected. Although they have a satisfactory permeability, they show high selectivity, i.e., greater values by Knudsen's ideal separation factor.

Table 1. GPU permeation of brass membranes.

MEMBRANES

\begin{tabular}{|c|c|c|c|c|c|c|c|}
\hline \multicolumn{3}{|c|}{ Pressure 10 bar } & \multirow{2}{*}{\multicolumn{2}{|c|}{ Membranethickness $\mathrm{mm}$}} & \multicolumn{3}{|c|}{ BRASS } \\
\hline Gases & $\begin{array}{c}\text { Molecular weight } \\
(\mathrm{g} / \mathrm{mol})\end{array}$ & Kineticdiameter $(\AA)$ & & & 0.085 & 0.196 & 0.205 \\
\hline H2 & 2.02 & 2.89 & GPU & Permeation & 41.09 & 1.64 & 3.10 \\
\hline He & 4.00 & 2.60 & & & 19.70 & 0.62 & 1.80 \\
\hline CH4 & 16.04 & 3.80 & & & 13.26 & 0.59 & 1.43 \\
\hline $\mathbf{N 2}$ & 28.01 & 3.64 & & & 9.86 & 0.39 & 0.82 \\
\hline $\mathbf{O 2}$ & 32.00 & 3.46 & & & 10.16 & 0.36 & 0.94 \\
\hline Ar & 39.95 & 3.40 & & & 8.18 & 0.30 & 0.84 \\
\hline $\mathrm{CO2}$ & 44.01 & 3.30 & & & 8.12 & 0.33 & 0.74 \\
\hline
\end{tabular}

(a)

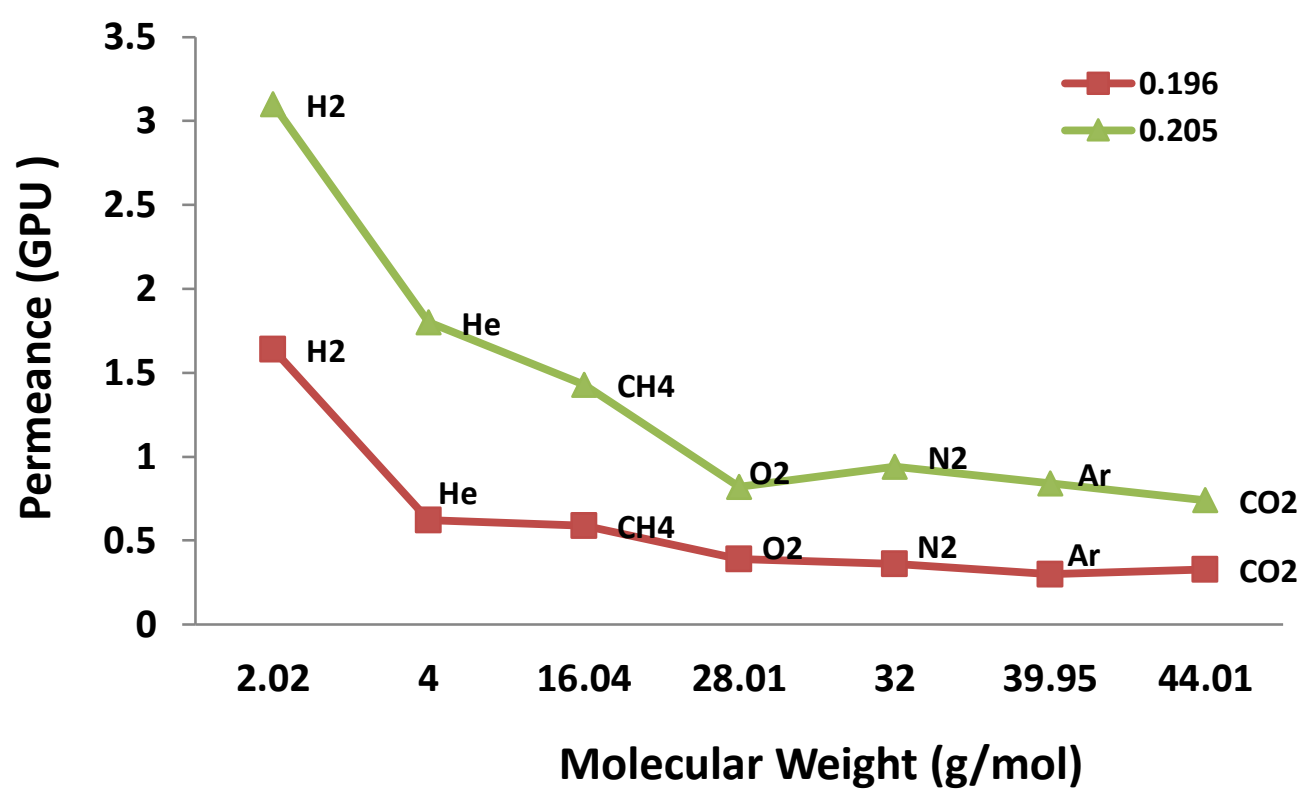


(b)

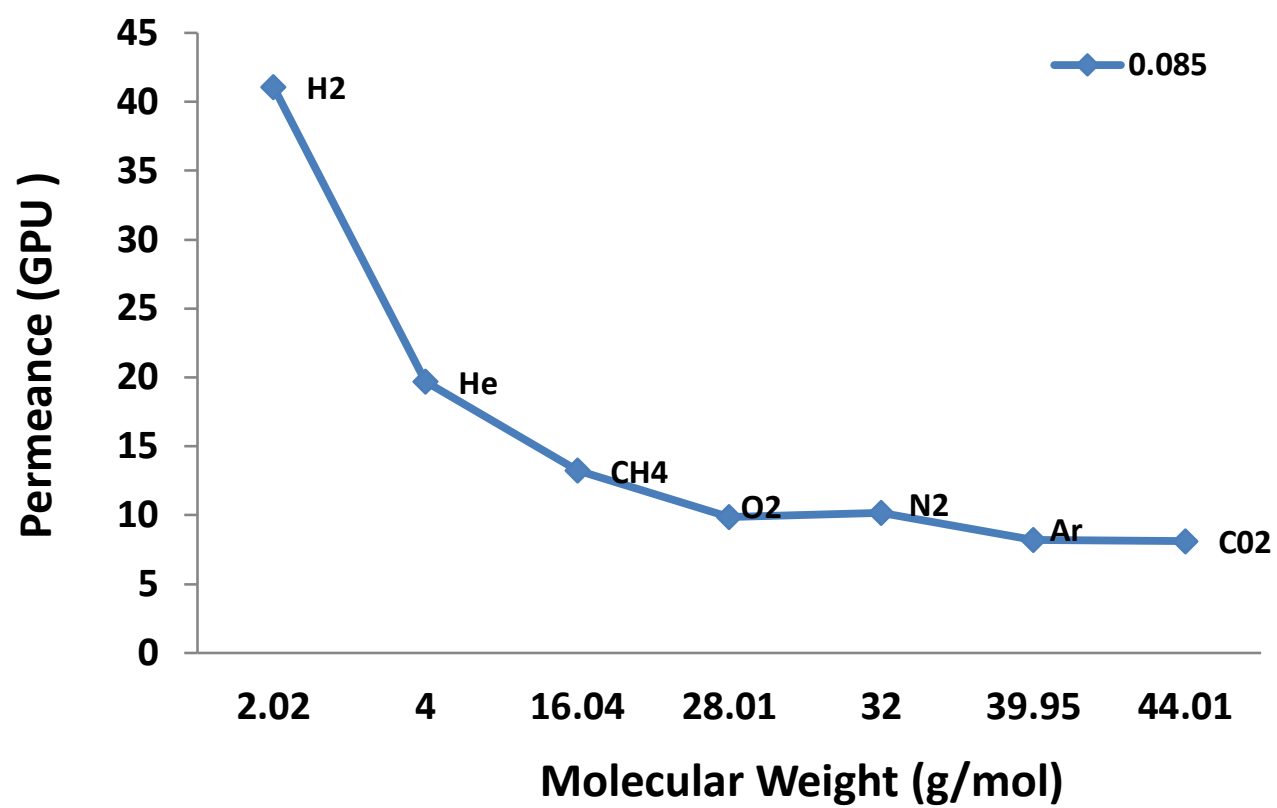

Figure 1. (a) GPU Permeation- Molecular Weight of Brass Membranes with thickness 0.196mm and 0.205mm respectively (b) GPU Permeation- Molecular Weight of Brass Membrane with thickness $0.085 \mathrm{~mm}$.

Permeability is affected by the molecular weight $(\mathrm{g} / \mathrm{mol})$ of each gas, resulting in relation: $\mathrm{H}_{2}>\mathrm{He}>\mathrm{CH}_{4}>\mathrm{N}_{2}>\mathrm{O}_{2}>\mathrm{Ar} \geq \mathrm{CO}_{2}$. The graph above shows the relationship between the three membranes. It is confirmed that the flow diffusion in the metal membrane is Knudsen diffusion, i.e., the lighter gases diffuse faster through the membranes.

Table 2. Ideal selectivity compared to Knudsen's selectivity.

\begin{tabular}{|c|c|c|c|c|c|c|c|}
\hline \multicolumn{8}{|c|}{ Membrane Ideal Selectivity } \\
\hline & Gases & H2/He & O2/N2 & H2/Ar & $\mathrm{CH} 4 / \mathrm{CO} 2$ & H2/CH4 & $\mathrm{N} 2 / \mathrm{CO} 2$ \\
\hline \multicolumn{2}{|c|}{ Knudsen } & 1.41 & 0.93 & 4.45 & 1.65 & 2.82 & 1.25 \\
\hline \multirow[t]{3}{*}{ BRASS } & $0,085 \mathrm{~mm}$ & 2.08 & 1.03 & 5.02 & 1.63 & 3.09 & 1.21 \\
\hline & $0,196 \mathbf{m m}$ & 2.64 & 0.92 & 5.46 & 1.78 & 2.77 & 1.18 \\
\hline & $0,205 \mathrm{~mm}$ & 1.72 & 1.14 & 3.69 & 1.93 & 2.16 & 1.1 \\
\hline
\end{tabular}

It is important to note that thickness is not a dependent variable. A comparative diagram of three membranes is presented below, with specific gas pairs selected for industrial-scale applications.

The membrane with a thickness of $0.085 \mathrm{~mm}$ regarding GPU values is high (8-41 GPU). The selectivity values match or exceed the Knudsen values (in the specific $\mathrm{H}_{2} / \mathrm{CH}_{4}$ gas pair, it presents the maximum values). The $0.196 \mathrm{~mm}$ thick membrane permeability has the lowest values ranging from 0.3-1.7 GPU but shows the maximum selectivity values in pairs $\mathrm{H}_{2} / \mathrm{He}$ and $\mathrm{H}_{2} / \mathrm{Ar}$ with 2.64 and 5.46, respectively.

The third membrane selected with a thickness of $0.205 \mathrm{~mm}$ the experimental values for the permeance are not high enough (0.7-3 GPU) as in the selectivity, its values are very close to the theoretical ones according to Knudsen or slightly higher in gas pairs.

Permeation data were measured and verified using a volume bubble gauge $(35 \mathrm{~mL})$ connected to the open end plus the device for all experiments. More specifically, the whole procedure is repeated with the difference that the volumetric gas flow is measured as a function of time $(\mathrm{mL} / \mathrm{s})$ at the exit with a bubble meter. 


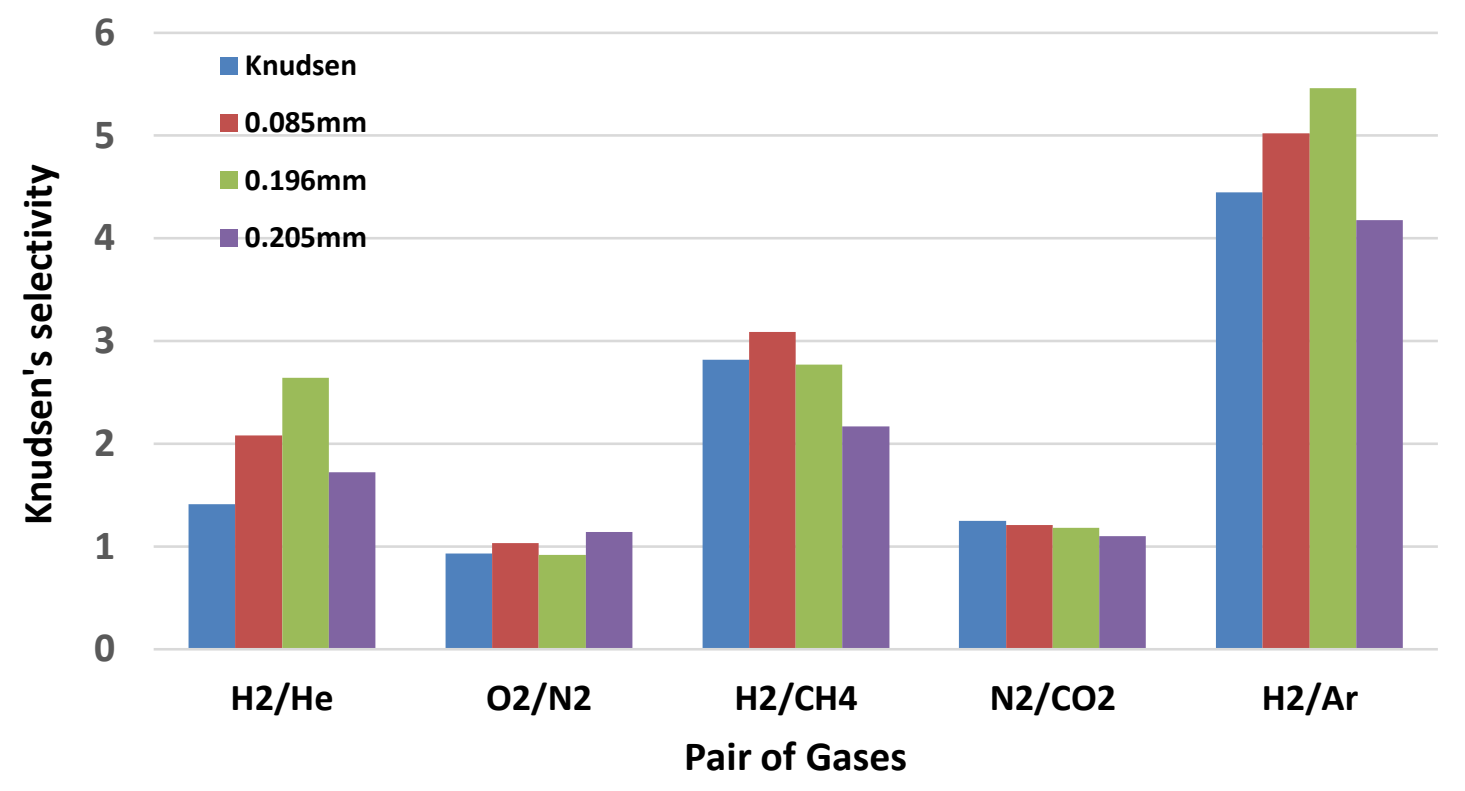

Figure 2. Ideal selectivity with specific gas pairs compared to Knudsen's selectivity.

\subsection{Pressure.}

The study of pressure affection in the permeability of metal membranes and how much it affects their performance showed after a series of experiments. The pressure remains constant at the desired value set (from 1 to 10 bar) in the high-pressure area, while at the same time, the pressure value in the low-pressure area $\left(48 \mathrm{~cm}^{3}\right)$ changes from 0 to 1 bar in time $\Delta \mathrm{t}$ as the gas passes the membrane. The experiments were performed at room temperature $\left(23^{\circ} \mathrm{C}\right)$ with the gas He.

(a)

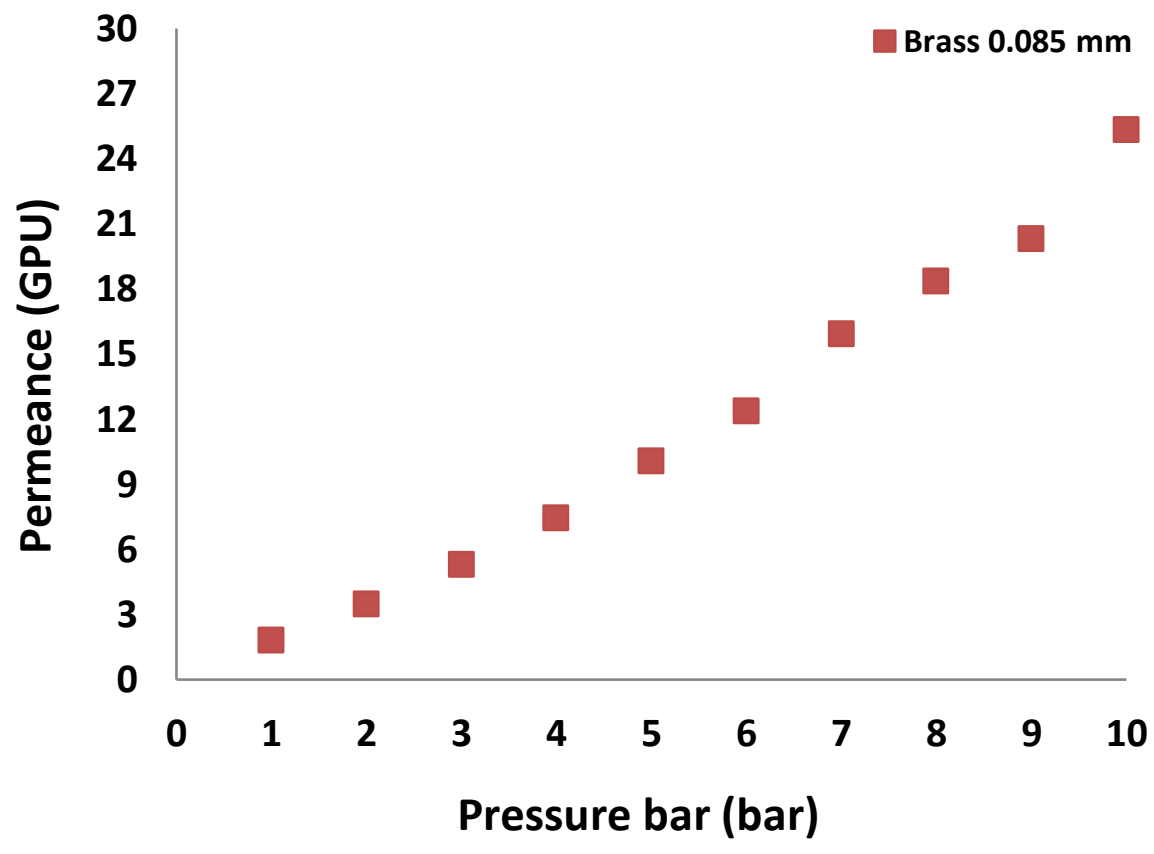


(b)

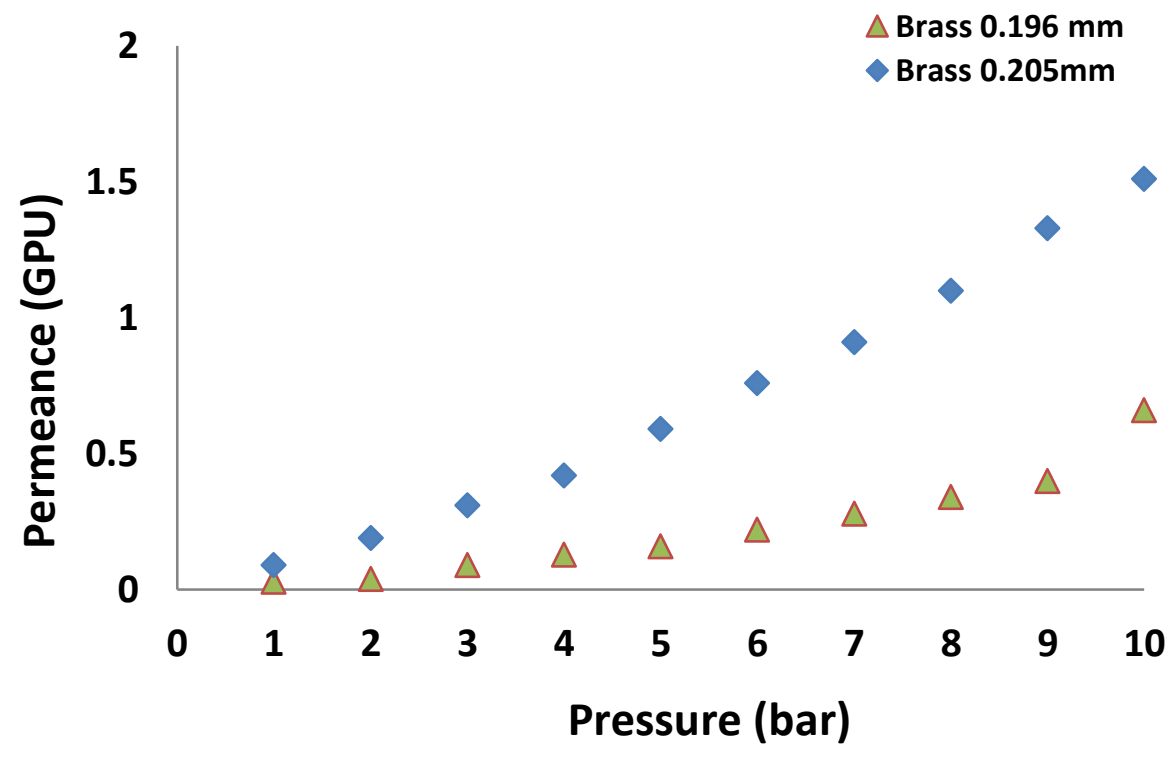

Figure 3. (a) GPU Permeation - Pressure of Brass Membranes with thickness $0.085 \mathrm{~mm}$. (b) GPU Permeation Pressure between the two Brass Membranes with thickness $0.196 \mathrm{~mm}$ and $0.205 \mathrm{~mm}$, respectively

The permeability of He on the third membrane $(0.205 \mathrm{~mm})$ shows higher values in the pressure range than the values of the $0.196 \mathrm{~mm}$ thick membrane, which means that the thickness can be defined as an independent parameter of permeability in this category of membranes.

\subsection{Temperature.}

Measurements were performed with $\mathrm{N}_{2}$ gas on a brass membrane to study their penetration at temperatures from -18 to $300^{\circ} \mathrm{C}$ and at pressures from $1-10 \mathrm{bar}$.

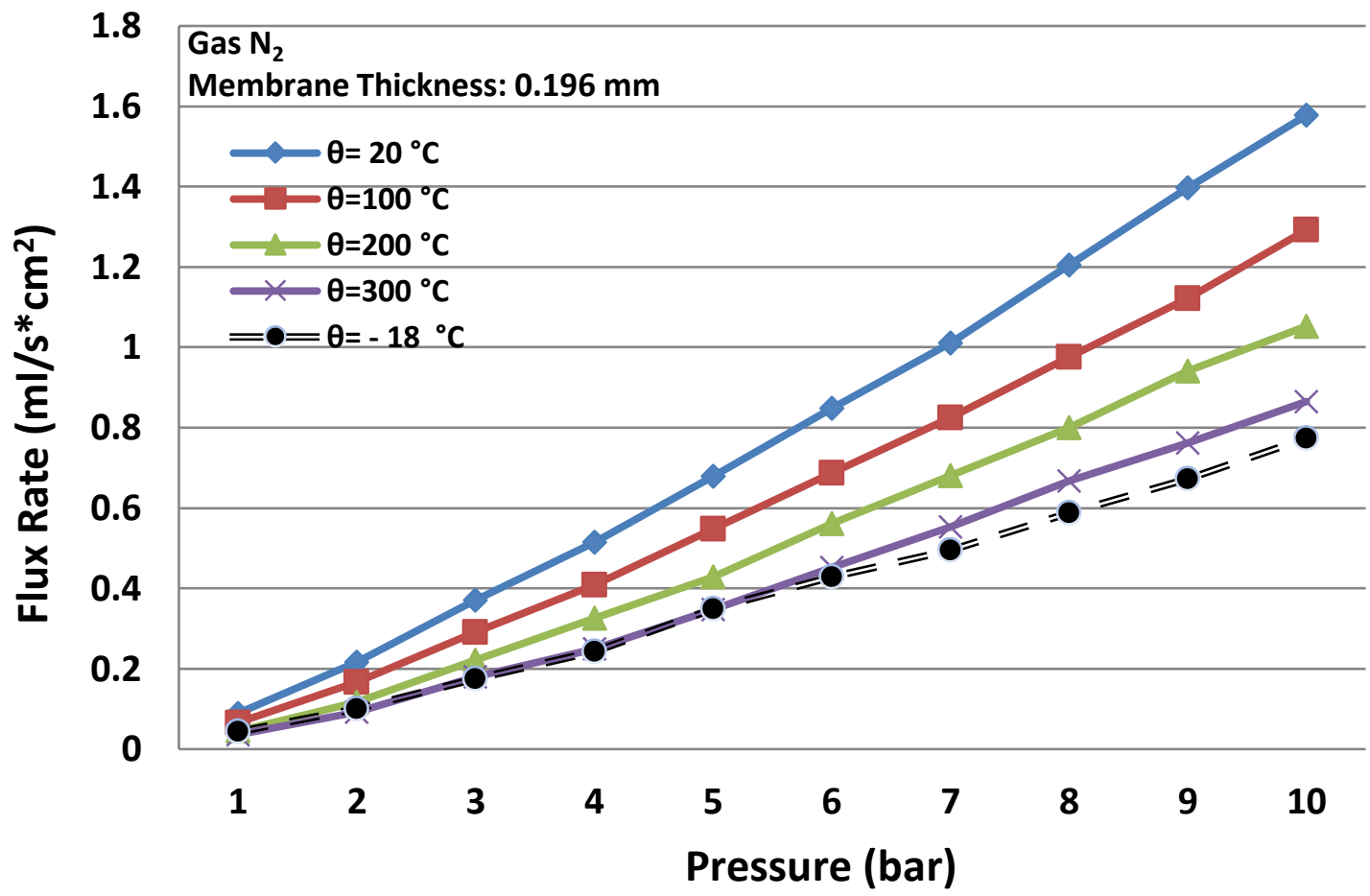

Figure 4. Flux Rate- Pressure with $\mathrm{N}_{2}$ gas for different ranges of temperature. 
The permeability of both gases increases with pressure and decreases with temperature, which means that the predominant diffusion is still Knudsen diffusion [33-34]. Linearity of flow values is also observed as the temperature increases per $100^{\circ} \mathrm{C}$ degrees, but of particular interest is the reduction of gas permeability at $-18^{\circ} \mathrm{C}$ as the pressure increases, where the permeation values coincide with the permeation values at a maximum temperature of $300^{\circ} \mathrm{C}$. This was followed by measurements for the membrane with a thickness of $0.196 \mathrm{~mm}$, with the pressure being kept constant at 10 bar.

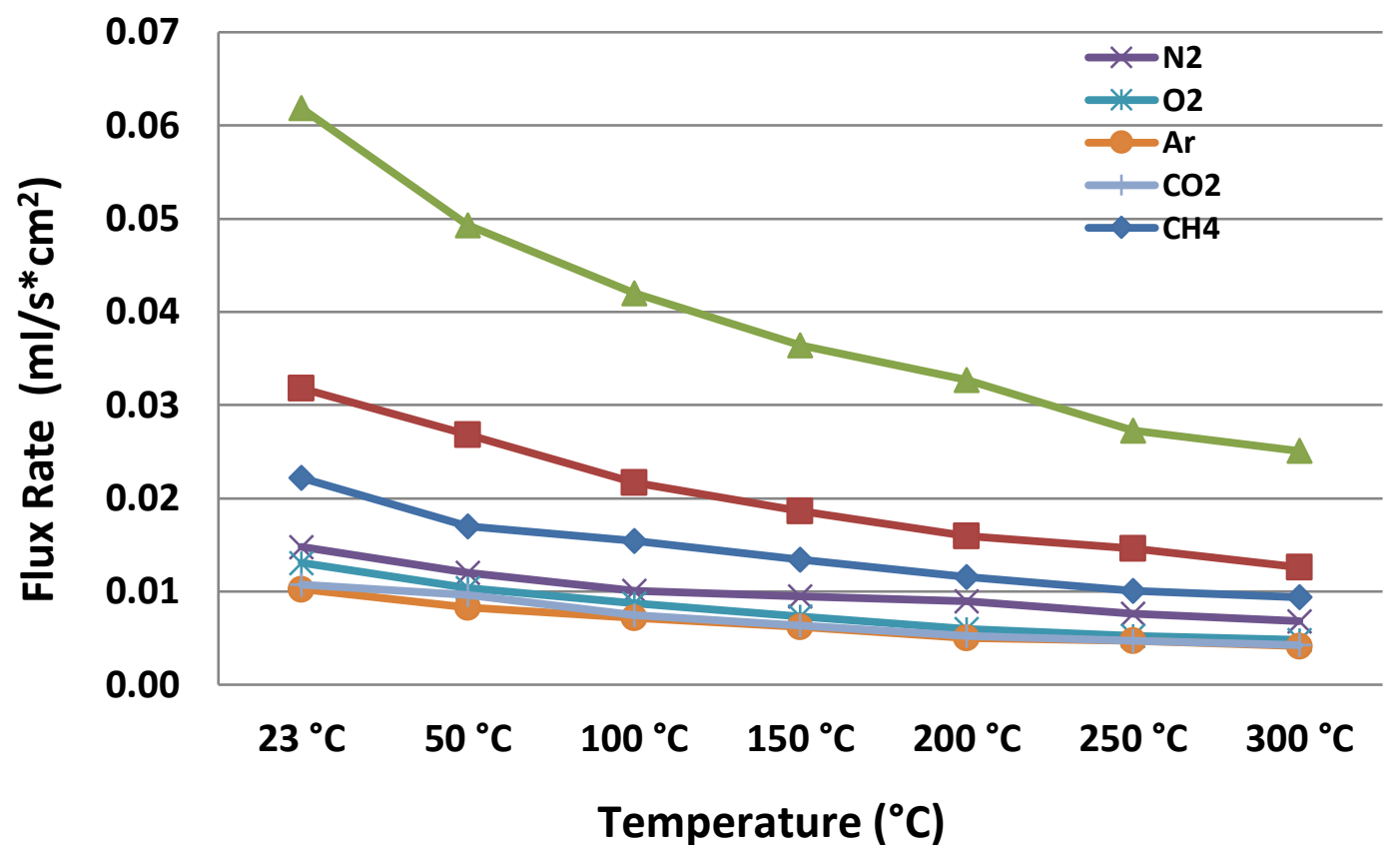

Figure 5. Flux Rate- Temperature for seven gases.

The permeate flux of all gases decreases with the increase of temperature in a permeable order $\mathrm{H}_{2}>\mathrm{H}_{\mathrm{e}}>\mathrm{CH}_{4}>\mathrm{N}_{2}>\mathrm{O}_{2}>\mathrm{A}_{\mathrm{r}} \geq \mathrm{CO}_{2}$, because the kinetic energy of molecules becomes greater, so the diffusion coefficient becomes greater [6]. Permeability is still determined by their molecular weight, except for $\mathrm{CO}_{2}$, where at low temperatures (up to $100^{\circ} \mathrm{C}$ ) it exhibits higher permeability values than $\mathrm{A}_{\mathrm{r}}$ due to the membrane diffusion transport mechanism acting on the membrane but at higher temperatures, as shown in the diagram, this diffusion is limited by the values of $\mathrm{CO}_{2}$ being lower or coinciding with $\mathrm{Ar}$. The gases $\mathrm{CH}_{4}, \mathrm{O}_{2}, \mathrm{CO}_{2}$, and $\mathrm{Ar}$ as shown in the diagram, were slightly affected by the increase in temperature while $\mathrm{H}_{2}$ and $\mathrm{H}_{\mathrm{e}}$ showed a significant change in which from $50^{\circ} \mathrm{C}$ they showed a decrease in its flow. $\mathrm{N}_{2}$ maintains a constant reduction in permeability.

Table 3. Ideal selectivity in different temperatures for specific pairs of gases. Ideal Selectivity

\begin{tabular}{|c|c|c|c|c|c|c|c|c|}
\hline & & \multicolumn{7}{|c|}{ BrassMembrane } \\
\hline Gases & Knudsen & $23^{\circ} \mathrm{C}$ & $50{ }^{\circ} \mathbf{C}$ & $100^{\circ} \mathrm{C}$ & $150{ }^{\circ} \mathrm{C}$ & $200{ }^{\circ} \mathrm{C}$ & $250{ }^{\circ} \mathrm{C}$ & $300{ }^{\circ} \mathrm{C}$ \\
\hline H2/He & 1.41 & 1.92 & 1.84 & 1.94 & 1.96 & 2.05 & 1.86 & 1.98 \\
\hline H2/CH4 & 2.82 & 2.77 & 2.91 & 2.70 & 2.71 & 2.80 & 2.68 & 2.67 \\
\hline H2/Ar & 4.45 & 6.03 & 5.97 & 5.84 & 5.86 & 6.57 & 5.83 & 6.04 \\
\hline $\mathrm{N} 2 / \mathrm{CO} 2$ & 1.25 & 1.38 & 1.25 & 1.35 & 1.49 & 1.70 & 1.61 & 1.60 \\
\hline O2/N2 & 0.93 & 1.13 & 1.16 & 1.16 & 1.29 & 1.50 & 1.45 & 1.42 \\
\hline
\end{tabular}


The ideal selectivity corresponds to the theoretical values according to Knudsen or shows an increasing trend, mainly at a temperature of $200^{\circ} \mathrm{C}$, as shown in the table above. Note that there is no imperfection in the surface substrate of the membrane (defects/cracks). In this case, it is considered a good mesoporous membrane.

\section{Conclusions and Future Perspectives}

\subsection{Permeability.}

The main feature of the studied membranes is that they have low permeability values for a series of gases such as $\mathrm{H}_{2}, \mathrm{H}_{\mathrm{e}}, \mathrm{CH}_{4}, \mathrm{~N}_{2}, \mathrm{O}_{2}, \mathrm{~A}_{\mathrm{r}}$, and $\mathrm{CO}_{2}$. The correlation of the thickness of the membranes concerning the permeation values of the studied gases is recorded as decreasing, with a linear behavior. The ideal selectivity values under consideration indicate that the predominant diffusion mechanism is that of Knudsen diffusion, where the probability of a diffuse molecule colliding with another molecule lags behind its probability of colliding with the pore walls. The fact that the measured permeability values are recorded on the molecular filter diffusion scale, serial diffusion, but the achieved permeability values recorded in the Knudsen separation region could be attributed to the existence of high tortuosity of the porous metal structure in combination with the existence of blind pores and high connectivity of the open pore path. Besides, surface diffusion was observed, where it acts in parallel with Knudsen diffusion in some membranes due to the interactions of $\mathrm{CO}_{2}$ with the films.

\subsection{Pressure.}

From all the experimental data that have emerged in the part of the effect of pressure, one can say with certainty that the permeability is a function of the thickness of the membrane, i.e., when there is an increase in thickness, there is a decrease in permeability and an increase in selectivity. Therefore, films with high thickness and low permeability should be tested at higher pressures (<10 bar) for further study.

\subsection{Temperature.}

To evaluate the performance of the membranes as a function of temperature, singlephase permeability measurements of pure components (individual gases) were performed in a temperature range from -18 to $300^{\circ} \mathrm{C}$ and at various pressures (1-10 bar). There were variations and changes in the values of permeability and selectivity, with the main feature being the reduction of the permeability with the increase of the temperature.

\subsection{Stability.}

The service life and durability of the membranes were also examined. The membranes can be used repeatedly for a long time (evaluated for more than 6 months in the present study), suggesting significant stability.

\subsection{Future work.}

In any case, the result of the existence of gas separation for metal films is a prototype for the field of membrane technology, and the further study both in the control of properties in real gaseous mixtures and in the further study of the parameters that determine its porous network creation is necessary. The control of the above membranes at separations in the liquid 
phase is a major future goal. Emphasis is placed on the study of wastewater treatment processes, with the basic studied system being that of the aqueous phase. Efforts to further improve the mechanism of creating the porous metal network are imperative and are planned to improve the techniques used and test new ones.

\section{Funding}

This research received no external funding.

\section{Acknowledgments}

This research has no external acknowledgments.

\section{Conflicts of Interest}

The authors declare no conflict of interest.

\section{References}

1. Winarta, J.; Meshram, A.; Zhu, F.; Li, R.; Jafar, H.; Parmar, K.; Liu, J.; Mu, B. Metal-organic frameworkbased mixed-matrix membranes for gas separation: An overview. J. Polym. Sci. 2020, 58, 2518-2546, https://doi.org/10.1002/pol.20200122.

2. Gao, S.; Wang, D.; Fang, W.; Jin, J. Ultrathin Membranes: A New Opportunity for Ultrafast and Efficient Separation.Adv. Mater. Technol.2020, 5, https://doi.org/10.1002/admt.201901069.

3. Wu, Q.; Zhao, X.; Peng, L.; Song, Y.; Selective Permeable Thin Films and Membranes. In Inorganic and Organic Thin Films: Fundamentals, Fabrication and Applications. Y. Song.; John Wiley \& Sons, Inc.: Beijing, China, 2021,1,447-488, https://doi.org/10.1002/9783527344987.ch14.

4. Pal, N.; Agarwal, M.Advances in materials process and separation mechanism of the membrane towards hydrogen separation .Int. J. Hydrog. Energy 2021, 46, 27062-27087, https://doi.org/10.1016/j.ijhydene.2021.05.175.

5. Tong, Z.; Sekizkardes, A.Recent Developments in High-Performance Membranes for CO2 Separation.Membranes, 2021, 11, 156, https://doi.org/10.3390/membranes11020156.

6. Okoro, E.; Josephs, R.; Sanni, S.E.; Yuven Nchila, Y.Advances in the Use of Nanocomposite Membranes for Carbon Capture Operations. International Journal of Chemical Engineering, 2021, 2021, 6666242, https://doi.org/10.1155/2021/6666242.

7. Goh, P.S.; Wong, K.C.; Ismail, A.F. Nanocomposite Membranes for Liquid and Gas Separations from the Perspective of Nanostructure Dimensions. Membranes, $\quad 2020, \quad 10, \quad 297$, https://doi.org/10.3390/membranes10100297.

8. Zhu, B.; Duke, M.; Dumee, L.F.; Merenda, A.; Ligneris, E.; Kong, L.; Hodgson, P.D.; Gray, S.Short Review on Porous Metal Membranes - Fabrication, Commercial Products, and Applications.Membranes2018, 8, 83,https://doi.org/10.3390/membranes8030083.

9. Goh, P.S.; Ismail, A.F. Structure and gas transport of nanocomposite membranes. In Nanocomposite Membranes for Gas Separation. 2020,101-123, https://doi.org/10.1016/B978-0-12-819406-5.00003-4.

10. Vermaak, Leandri, Neomagus, Hein W. J. P.; BessarabovDmitri, G.Recent Advances in Membrane-Based Electrochemical Hydrogen Separation: A Review.Membranes, 2021, 11, 2, https://doi:10.3390/membranes11020127.

11. Cardoso, S.P.; Azenha, I.S.; Lin, Z.; Portugal, I.; Rodrigues, A.E.; Silva, C.M. Inorganic Membranes for Hydrogen Separation. Separation and Purification Reviews, 2018, 47, 229-266, https://doi.org/10.1080/15422119.2017.1383917.

12. Xing, W.H. Ceramic Membranes. In Membrane-Based Separations in Metallurgy: Principles and Applications. $1^{\text {st }}$ ed.;Jiang L. Y. and Li. N.; Elsevier Ltd.: Hunan, China 2017, 357-370, https://doi.org/10.1016/B978-0-12-803410-1.00014-1. 
13. Abdullah, N.; Rahman, M.A.; Othman, M.H.D.; Membranes and Membrane Processes: Fundamentals. In Current Trends and Future Developments on (Bio-) Membranes: Photocatalytic Membranes and Photocatalytic Membrane Reactors. A. Basile, S. Mozia and R. Molinari. Elsevier: Malaysia 2018, 45-70.

14. Ladewig, B.; Al-Shaeli, M.N.Z.Fundamentals of Membrane Processes. In Fundamentals of Membrane Bioreactors: Materials, Systems and Membrane Fouling. Springer Transactions in Civil and Environmental Engineering 2017, 13-37, https://doi.org/10.1007/978-981-10-2014-8_2.

15. He, Y.-H. Metal Membranes. In Membrane-Based Separations in Metallurgy,Principles and Applications. $1^{\text {st }}$ ed.; N. Jiang and L. Ying.; Elsevier Inc.: Hunan, China 2017, 371-390, https://doi.org/10.1016/B978-012-803410-1.00015-3.

16. Xiao, L.S. Membrane-Based Separation. In Membrane-Based Separations in Metallurgy, Principles and Applications. $1^{\text {st }}$ ed.;L. Y. Jiang and N. Li.; Elsevier Inc.: Hunan, China: 2017, 19-55.

17. Alique, D. Processing and Characterization of Coating and Thin Film Materials. In Advanced Ceramic and Metallic Coating and Thin Film Materials for Energy and Environmental Applications. J. Zhang and Y.-G. \& Jung; Springer International Publishing: Switzerland, 2018, $27-72$.

18. Arzani, F.A.; Neto, A.C.R.; Terra, N.M.; Cardoso, V.L.; Reis, M.H.M. Influence of external mass transfer and support resistances for hydrogen permeation through composite palladium membranes, AIChEJournal, Environ Prog Sustainable Energy. 2021, e13692, https://doi.org/10.1002/ep.13692.

19. Tanaka, D.A.P.; Medrano, J.A.; Sole, J.L.V.; Gallucci, F.Metallic membranes for hydrogen separation. In Current Trends and Future Developments on (Bio-) Membranes: Recent Advances in Metallic Membranes. $1^{\text {st }}$ ed.;Zhang, Jing, Jung, Yeon-Gil; Elsevier: The Netherlands, 2020,1-29, https://doi.org/10.1016/B978-012-818332-8.00001-6.

20. Bientinesi, M.;Petarca, L. H2 Separation from Gas Mixtures through Palladium Membranes on Metallic Porous Supports. Chemical Enigineering Transactions, 2011, 24, 763-768, https://doi.org/10.3303/CET1124128.

21. Adhikari, S.; Fernando, S.Hydrogen membrane separation techniques.Ind. Eng. Chem. Res. 2006, 45, 875881, https://doi.org/10.1021/ie0506441.

22. Lin, Y. S.Inorganic Membranes for Gas Separation and Purification. Membrane 2006,31, 170-173, https://doi.org/10.5360/membrane.31.170.

23. Baker, R. W. Membrane Technology and Applications. 2nd. ed. John Wiley \& Sons Ltd, 2004, https://doi.org/10.1002/0470020393.

24. Howard, B.; Killmeyer, R. ; Rothenberger, K.; Cugini, A.; Morreale, B.; Enick,R.; Bustamante F. Hydrogen permeance of palladium-copper alloy membranes over a wide range of temperatures and pressures. Journal of Membrane Science 2004, 241, 207-218, https://doi.org/10.1016/j.memsci.2004.04.031.

25. Ramírez-Santos, Á.A.; Castel, C.; Favre, E.A review of gas separation technologies within emission reduction programs in the iron and steel sector: Current application and development perspectives.Separation and Purification Technology 2018, 194, 425-442, https://doi.org/10.1016/j.seppur.2017.11.063.

26. Sridhar, S.; Bee, S.; Bhargava, S.;Membrane-based Gas Separation: Principle, Applications and Future Potential.Chem Eng Dig. 2014, 1, 1-25.

27. Pandey, P.; Chauhan, R.S.Membranes for gas separation.Progress in Polymer Science, 2001, 26, 853-893, https://doi.org/10.1016/S0079-6700(01)00009-0.

28. Kamble, A. R.; Patel, C. M.; Murthy, Z.V.P. A review on the recent advances in mixed matrix membranes for gas separation processes.Renewable and Sustainable Energy Reviews, 2021, 145, https://doi.org/10.1016/j.rser.2021.111062.

29. Singh, H.; Saxena, P.; Puri, Y.M.;The manufacturing and applications of the porous metal membranes: A critical review.CIRP Journal of Manufacturing Science and Technology 2021, 33, 339-368, https://doi.org/10.1016/j.cirpj.2021.03.014.

30. Iulianelli, A.; Drioli, E.Membrane engineering: Latest advancements in gas separation and pretreatment processes, petrochemical industry and refinery, and future perspectives in emerging applications. Fuel Processing Technology 2020, 206, https://doi.org/10.1016/j.fuproc.2020.106464.

31. Meis, D.D.Gas transport through porous membranes. ENEA 2017, https://doi.org/10.13140/RG.2.2.25450.72641.

32. Basile, A.; Gallucci, F.Membranes for Membrane Reactors: Preparation, Optimization and Selection. John Wiley \& Sons, Ltd.2011, https://doi.org/10.1002/9780470977569. 
33. Conde, J.J.; Maroño, M.; Sánchez-hervás, J.M.Pd-Based Membranes for Hydrogen Separation : Review of Alloying Elements and Their Influence on Membrane Properties. Separation and Purification Reviews 2017,46, 2, 152-177, https://doi.org/10.1080/15422119.2016.1212379.

34. Phair, J.W.; Badwal, S.P.S.Materials for separation membranes in hydrogen and oxygen production and future power generation. Science and Technology of Advanced Materials. 2006, 7, 792-805, https://doi.org/10.1016/j.stam.2006.11.005. 